\title{
The Role of Cutaneous Receptors in the Menton Tap Silent Period
}

J. O. BAILEY, JR*., W. D. MCCALL, JR.(1), N. N. MANSOUR, M. M. ASH, JR.

Stomatognathic Laboratory, Department of Occlusion, School of Dentistry, University of Michigan, Ann Arbor, Michigan 48109; *Present address, Dental School, Division of Occlusion, University of Texas Health Science Center, San Antonio, Texas 78284

The neuromuscular mechanisms of the electromyographic silent period are poorly understood but clinically significant. Our purpose was to isolate the contribution of cutaneous afferents from the chin to the latency and the duration of the EMG silent period. Under the conditions of our experiment, the afferents of the mental nerve have no observable influence on the latency or the duration of the silent period educed by a menton tap.

\section{J Dent Res 58(1):506-510, January 1979}

Evidence exists for the clinical significance of EMG silent period duration measurements in TMJ muscle-pain-dysfunction patients. ${ }^{14}$ Several reports ${ }^{14}$ furnish evidence indicating that the duration of the menton tap silent period is longer in patients with TMJmuscle-pain dysfunction than in clinically normal subjects. The neuromuscular mechanisms responsible for the reflex inhibition of the silent period, however, are poorly understood. Inhibition of jaw closing muscle activity has been reported by mechanical taps delivered to the menton, ${ }^{1-5}$ teeth, ${ }^{6-9}$ and other locations; 10,11 by electrical stimulation of facial areas, ${ }^{12-15}$ oral mucosa, 16 and tooth pulp; $;^{17-19}$ by tapping the teeth together voluntarily in dentate subjects 20,21 or in edentulous individuals with complete dentures; $;^{22,23}$ and even auditory stimuli. ${ }^{24}$

In view of the reported clinical significance of the silent period duration elicited by a menton tap during a maximal clench, the mechanisms of this specific method are especially important. The recording of silent periods educed by tooth taps before and after anesthesia of the tooth ${ }^{6-9}$ has established that receptors in or around the periodontal ligament can cause silent periods.

(1) Present Address: Department of Oral Medicine, School of Dentistry, State University of New York at Buffalo, Buffalo, N.Y. 14214

Received for publication October 21, 1977.

Accepted for publication March 10, 1978.

Supported by USPHS Grant DE 02731
In one effort ${ }^{25}$ to isolate the afferents in the menton-tap method, sequential quadrant anesthesia was administered to three volunteers. Apart from the small number of subjects, that report may possibly be criticized for not considering the contribution to the silent period phenomenon of cutaneous afferents from the area being tapped.

The purpose of the present study was to isolate the contribution of the cutaneous afferents from the chin to the latency and duration of the EMG silent period educed by a tap to the menton during a maximal clench.

\section{Methods and material.}

Twelve students and staff from the School of Dentistry at the University of Michigan comprised the subjects for this study. Eleven were male and one was female. The ages ranged from 22 years to 39 years, with an average of 29 years. Informed consent was obtained from each subject prior to the experiment. Subjects were required to be free of signs and symptoms, both historically and presently, of TMJ-muscle-pain dysfunction. The signs and symptoms considered were pain or tenderness in the area of the TMJ or muscles of mastication, limitation of mandibular movement, and joint sounds.

The electrical activity of the right and left masseter muscles was recorded, using bipolar surface electrodes and commercially available amplifiers. A reflex hammer was used to tap the chin, and an accelerometer was mounted on the reflex hammer to indicate the time of the tap. All data were recorded on magnetic tape for later replay in time expansion onto a polygraph. Slowing the tape speed by a factor of four and running the polygraph paper at $50 \mathrm{~mm} /$ $\mathrm{sec}$ gave a conversion factor of $5 \mathrm{~ms}$ per $\mathrm{mm}$ of paper. A vernier caliper was used to measure latency and duration of the silent period to $0.1 \mathrm{~mm}$ which represents $0.5 \mathrm{~ms}$. 
The measurement of the silent period was taken from the peak of the last spike before the period of silence to the peak of the first spike which was part of continuing or ongoing activity after the period of silence. The latency was measured from the first deflection of the accelerometer trace from its baseline to the last peak preceding the inhibition. Each subject was seated in a dental chair with the head supported so that the ala-tragus line was parallel to the floor. Each subject was asked to clench his or her teeth together with maximal force in the intercuspal position $\mathrm{CO}$ while a series of 5 taps was delivered to the menton with the reflex hammer. The monitoring of bite force and tap force was not attempted in this study. Evidence exists 5,27 indicating that these two input parameters do not influence the duration of the silent period following a menton tap.

The electromyograms were repeated after the right and left mental nerves were anesthetized as they emerge from the mental foramen by injecting $1 \mathrm{cc}$ of $2 \%$ Xylocaine with 1/100,000 Epinephrine. Anesthesia was confirmed both by subjective report and by the absence of sensation when probed with a dental explorer.

Latency results were obtained from five subjects; duration results following unilateral anesthesia were obtained from another five subjects; and duration results before and after bilateral anesthesia were obtained from all twelve subjects. The results were analyzed statistically using analysis of variance for repeated measures on the same subjects ${ }^{26}$ to compare the mean latencies or mean durations.

\section{Results.}

Typical results showing the latency and duration of the silent period before and after bilateral mental nerve anesthesia are shown in Fig. 1.

The latencies of the silent period for five subjects before and after bilateral mental nerve anesthesia for both right and left masseter muscles are given in Table 1. Each entry for a particular muscle, anesthesia state, and subject is the average over the five sequential taps. The differences in mean latency among muscles and anesthesia states, given in Table 1 , are not statistically significant $(.05<\mathrm{p}<0.1)$.

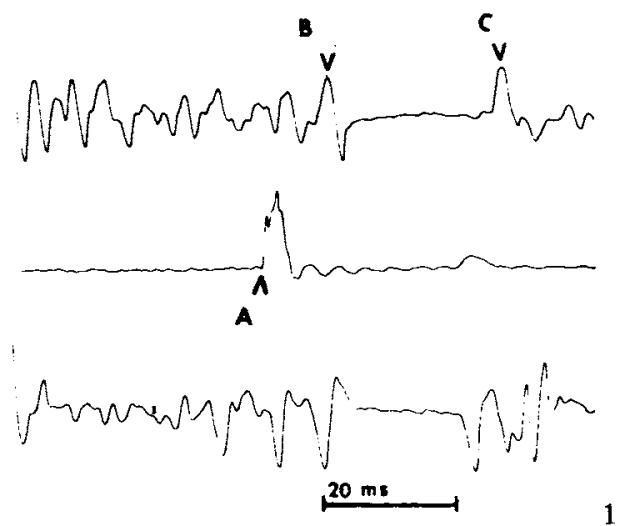

$1 \mathrm{~A}$

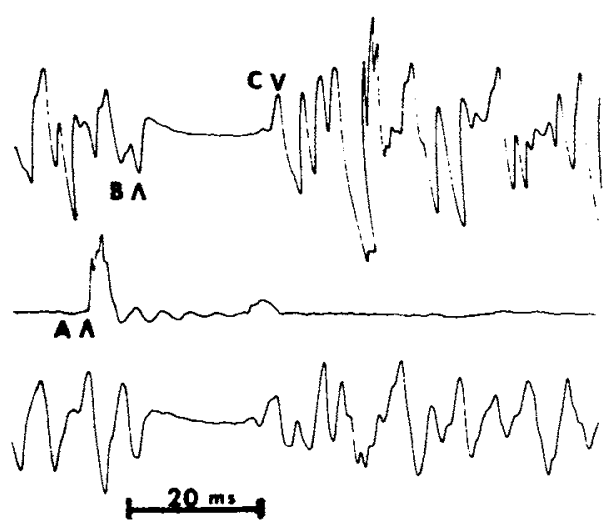

$1 B$

Fig. 1. A. Data from subject before anesthesia. B. Data from subject after anesthesia.

Labels: A - Accelerometer trace

B - Beginning of silent period

C - End of silent period

To investigate the influence of anesthesia on the duration of the silent period, a series of statistical tests was performed using, as one-way factors, the taps in sequence, the muscles, and the number of nerves anesthetized.

In 12 subjects the mean silent period durations for each of four taps prior to anesthesia and four taps after bilateral anesthesia were compared. The fifth tap was omitted because of missing data in some subjects. In each subject the durations were averaged over the available muscles for this test. No statistically significant differences in mean silent period duration were observed among the eight taps $(.05<\mathrm{p}<0.1)$. The mean durations and their standard deviations for 
TABLE 1

LATENCY (MS) OF THE SILENT PERIOD

\begin{tabular}{|c|c|c|c|c|}
\hline \multirow[b]{2}{*}{ Subject } & \multicolumn{2}{|c|}{ No Anesthesia } & \multicolumn{2}{|c|}{ Bilateral Anesthesia } \\
\hline & $\begin{array}{c}\text { Right } \\
\text { Masseter }\end{array}$ & $\begin{array}{c}\text { Left } \\
\text { Masseter }\end{array}$ & $\begin{array}{c}\text { Right } \\
\text { Masseter }\end{array}$ & $\begin{array}{c}\text { Left } \\
\text { Masseter }\end{array}$ \\
\hline 1 & 10.50 & 9.90 & 10.80 & 9.30 \\
\hline 2 & 10.70 & 10.20 & 10.25 & 10.25 \\
\hline 3 & 12.00 & 11.00 & 10.40 & 9.90 \\
\hline 4 & 8.40 & 7.20 & 8.30 & 8.00 \\
\hline 5 & 9.70 & 8.80 & 9.75 & 9.98 \\
\hline Mean & 10.26 & 9.42 & 9.90 & 9.47 \\
\hline Std. Dev. & 1.33 & 1.47 & .97 & .89 \\
\hline
\end{tabular}

the four sequential taps prior to anesthesia were $25.06 \pm 2.90,24.80 \pm 3.68,24.67 \pm$ 3.71 , and $24.63 \pm 3.51 \mathrm{~ms}$. After bilateral anesthesia the mean durations were 24.10 $\pm 4.15,23.39 \pm 3.61,23.28 \pm 3.93$, and $23.84 \pm 3.57 \mathrm{~ms}$.

In 10 subjects the mean silent period duration was compared between two muscles before and after bilateral anesthesia of the mental nerve. The mean duration for the right masseter was $24.44 \pm 3.50$ before and $23.94 \pm 4.17 \mathrm{~ms}$ after anesthesia. For the left masseter the mean was $24.75 \pm$ 4.75 before and $24.51 \pm 3.62 \mathrm{~ms}$ after anesthesia. These mean values did not differ with statistical significance $(.05<\mathrm{p}<0.1)$. Since no difference was shown in the sequence of taps, they were averaged for this test. In subsequent tests, durations were averaged over both muscles and taps for each subject.

In 5 subjects silent periods were recorded prior to any anesthesia, after anesthesia of the left mental nerve had taken effect, and after anesthesia of both left and right mental nerves had taken effect. The results are given in Table 2. The mean durations did not differ with statistical significance $(F=$
$0.43)$.

\section{Discussion.}

Under the conditions of the experiment, the cutaneous afferents innervated by the mental nerve had no observable influence on the latency or the duration of the silent period. Under other experimental conditions, such as electrical stimulation, the cutaneous receptors can and do provide sufficient inhibition to produce a silent period.12-15 Similarly, the periodontal receptors $^{6-9}$ and the oral mucosa ${ }^{16}$ can inhibit the motoneurons.

It is believed, however, that the numerous methods of supplying input cannot be compared in a simple way. As noted above, electrical stimulation of the cutaneous area causes silent periods, while the role of cutaneous afferents using a mechanical tap must be excluded by the present results.

The only other studies directly addressing the mechanism of the silent period following the menton tap are the anesthesia study of Bessette et al., ${ }^{25}$ and the reports on the effect of bite force on silent period duration. 5,27

TABLE 2

DURATION (MS) OF THE SILENT PERIOD

\begin{tabular}{cccc}
\hline Subject & $\begin{array}{c}\text { Before } \\
\text { Anesthesia }\end{array}$ & $\begin{array}{c}\text { Left Side } \\
\text { Anesthesia }\end{array}$ & $\begin{array}{c}\text { Bilateral } \\
\text { Anesthesia }\end{array}$ \\
\hline 1 & 26.58 & 24.02 & 21.38 \\
2 & 19.55 & 20.20 & 18.35 \\
3 & 22.80 & 25.65 & 26.32 \\
4 & 24.56 & 25.08 & 23.44 \\
5 & 22.58 & 23.25 & 23.87 \\
Mean & 23.21 & 23.64 & 22.67 \\
Std. Dev. & 2.60 & 2.14 & 2.99 \\
\hline
\end{tabular}


The point of departure for the present study was the criticism of Bessette et al.,25 for not considering cutaneous afferents. Our results indicate that this criticism was not, in fact, serious: the cutaneous afferents do not alter their conclusions.

\section{Conclusions.}

Under the conditions of the experiment, the following conclusions can be made:

1. There is no statistically significant difference in the mean latency or mean duration of the silent periods for the right and left masseter muscles.

2. There are no statistically significant differences in the mean latency or in the mean duration of the silent period after unilateral or bilateral anesthesia of the mental nerve.

3. The cutaneous afferents of the mental nerve have no observable role in silent period latency or duration following a menton tap during intercuspal clench.

\section{REFERENCES}

1. BESSETTE, R. W.; BISHOP, B.; and MOHL, N. D.: Duration of masseteric silent period in patients with TMJ syndrome, J. Appl. Physiol. 30:864-869, 1971.

2. WIDMALM, S. E.: The silent period in the masseter muscle of patients with TMJ dysfunction, Acta Odont. Scand. 34:43-52, 1976.

3. BAILEY, J. O., JR.; MCCALL, W. D., JR.; and ASH, M. M., JR.: Electromyographic silent periods and jaw motion parameters: quantitative measures of temporomandibular joint dysfunction, J. Dent. Res. 56:249-253, 1977.

4. MCCALL, W. D., Jr.; GOLDBERG, S. B.; UTHMAN, A. A.; and MOHL, N. D.: Symptom severity and silent periods: preliminary results in TMJ dysfunction patients, $N . Y$. State Dent. J. 44:58-60, 1978.

5. BAILEY, J. O., JR.; MCCALL, W. D., JR.; and ASH, M. M., JR.: The influence of mechanical input parameters on the duration of the electromyographic silent period in man, Arch. Oral Biol., 22:619-623, 1977.

6. BEAUDREAU, D. E.; DAUGHERTY, W. F.; and MASLAND, W. S.: Two types of motor pause in masticatory muscle, Amer. J. Physiol. 216:16-21, 1969.

7. GOLDBERG, L. J.: Masseter muscle excitation induced by stimulation of periodontal and gingival receptors in man, Brain Res. 32: 369-381, 1971.
8. HANNAM, A. G.; MATTHEWS, B.; and YEMM, R.: Receptors involved in the response of the masseter muscle to tooth contact in man, Arch. Oral Biol. 15:17-24, 1970.

9. SESSLE, B. J. and SCHMITT, A.: Effects of controlled tooth stimulation on jaw muscle activity in man, Arch. Oral Biol. 17:1597$1607,1972$.

10. WATT, D. M.; TURNBULL, J. R.; SAVERI, M.; BEYLI, M. S.; and AGUILAR, E.: The influence of percussion, occlusion, and mastication on the occurrence of silent periods in masseter muscle activity, J. Oral Rehab., 3:371-385, 1976 .

11. GILLINGS, B. R. D., and KLINEBERG, I. J.: Latency and inhibition of human masticatory muscles following stimuli, J. Dent. Res. 54:269-279, 1975 .

12. HUFSCHMIDT, H. J., and SPULER, H: Monoand polysynaptic reflexes of the trigeminal muscles in human beings, $J$. Neurol. Neurosurg, Psychiat. 25:332-335, 1962.

13. BRATZLAVSKY, M.: Pauses in activity of human jaw closing muscle, Exp. Neurol. $36: 160-165,1972$.

14. GODAUX, E., and DESMEDT, J. E.: Exteroceptive suppression and motor control of the masseter and temporalis muscles in normal man, Brain Res. 85:447-458, 1975.

15. DESMEDT, J. E., and GODAUX, E.: Habituation features of exteroceptive reflexes in normal man and the effect of voluntary innervation, Brain Res. 106:21-29, 1976.

16. YEMM, R.: Reflex jaw opening following electrical stimulation of oral mucous membrane in man, Arch. Oral Biol. 17:513-523, 1972.

17. BRATZLAVSKY, M.; DEBOEVER, J.; and VAN DER EECKEN, H.: Tooth pulpal reflexes in jaw musculature in man, Arch. Oral Biol. 21:491-493, 1976.

18. SESSLE, B. J., and GREENWOOD, L. F.: Inputs to trigeminal brain stem neurones from facial, oral, tooth pulp, and pharyngolaryngeal tissues: I. Responses to innocuous and noxious stimuli, Brain Res. 117:211-226, 1976.

19. GREENWOOD, L. F., and SESSLE, B. J.: Inputs to trigeminal brain stem neurones from facial, oral, tooth pulp, and pharyngolaryngeal tissues: II. Role of trigeminal nucleus caudalis in modulating responses to innocuous and noxious stimuli, Brain Res. 117:227-238, 1976.

20. BRENMAN, H. S.; BLACK, M. A.; and COSLET, J. G.: Interrelationship between the electromyographic silent period and dental occlusion, J. Dent. Res. 47:502, 1968.

21. BEEMSTERBOER, P. L.; MCNAMARA, D. C.; HOLDEN, S.; and ASH, M. M., JR.: The effect of bite plane splint on the electromyographic silent period duration. $J$. Oral Rehab. 3:349$352,1976$.

22. MATTHEWS, B. and YEMM, R.: A silent period in the masseter electromyogram follow- 
ing tooth contact in subjects wearing full dentures, Arch. Oral Biol. 15:531-535, 1970.

23. NAGASAWA, T.; SASAKI, H.; and TSURU, H.: Masseteric silent period after tooth contact in full denture wearers, $J$. Dent. Res. 55: $314,1976$.

24. MEIER-EWART, K.; GLEITSMANN, K.; and REITER, F.: Acoustic jaw reflex in man: its relationship to other brain-stem microreflexes, Electroenceph. Clin. Neurophysiol. $36: 229-237,1974$.
25. BESSETTE, R. W.; MOHL, N.D.; and BISHOP, $B$ : Contribution of periodontal receptors to the masseteric silent period, J. Dent. Res. 53:1196-1203, 1974.

26. WINER, B. J.: Statistical Principles in Experimental Design, Sec. ed., McGraw-Hill, N. Y., p. 261, 1971 .

27. BESSETTE, R. W., et al.; Effect of biting force on the duration of the masseteric silent period. J. Dent. Res. 52:426-430, 1973.

\section{ANNOUNCEMENT}

March 19-23, 1980

International Symposium on Sedation and Anesthesia in Dentistry

Sponsored by the N. B. Jorgensen Memorial Library

Loma Linda University

Place: San Diego Hilton Hotel

For further information, write:

Gerald D. Allen, M.D.

Department of Anesthesiology

UCLA School of Medicine

Los Angeles, California 90024

\section{CORRECTED ANNOUNCEMENT}

Conference: 9th Annual Conference on the Immunopathology of the Skin

Theme: Basic and clinical immunology of the skin, a simplified review

Date: May 24 and 25, 1979

Place: Niagara Falls, New York - Niagara Hilton Hotel

Organizers: Ernst H. Beutner and Russell J. Nisengard

Topics: Short reviews of immunology; basic and practical aspects of SLE and bullous diseases; what's new in immunodermatology; autoimmunity and treatment of psoriasis.

Registration: Fee - $\$ 95.00$ - Send to Mrs. Gloria Griffin, SUNY/Buffalo, 219 Sherman Hall, Buffalo, New York 14214. The deadline for registration is April 30, 1979.

Approved by: This course meets the criteria for category 1 of the American Academy of Dermatology Continuing Medical Education Award and of the Physicians Recognition Award of the AMA. Credit is given on an hour-for-hour basis. 